\title{
A Numerical Model for the Dynamic Simulation of a Recirculation Single- Effect Absorption Chiller
}

\author{
Matthieu ZINET, Romuald RULLIERE*, Philippe HABERSCHILL \\ Université de Lyon, CNRS \\ INSA-Lyon, CETHIL, UMR 5008, F-69621, Villeurbanne, France \\ Université Lyon 1, F-69622, France \\ *corresponding author: Tel. +33472436305 - Fax. +33472438811 \\ *E-mail address: romuald.rulliere@insa-lyon.fr
}

\begin{abstract}
A dynamic model for the simulation of a new single-effect water/lithium bromide absorption chiller is developed. The chiller is driven by two distinct heat sources, includes a custom integrated falling film evaporator-absorber, uses mixed recirculation and is exclusively cooled by the ambient air. Heat and mass transfer in the evaporator-absorber and in the desorber are described according to a physical model for vapour absorption based on Nusselt's film theory. The other heat exchangers are handled using a simplified approach based on the NTUeffectiveness method. The model is then used to analyze the chiller response to a step drop of the heat recovery circuit flow rate, and to a sudden reduction of the cooling need in the conditioned space. In the latter case, a basic temperature regulation system is simulated. In both simulations, the performance of the chiller is well represented and consistent with expectations.
\end{abstract}

Keywords: absorption; chiller; modelling; transient; water-lithium bromide; falling film 


\section{Nomenclature}

Symbol

\section{Variables - Latin letters}

\section{a}

$c$

C

Cp

D

e

$g$

$\dot{G}$

$h$

k

L

M

$\tilde{M}$

$\dot{m}$

$N_{T}$

$N T U$

$p$
$\dot{Q}$

$\dot{Q}$

$R e$

S

$t$

$T$

$u$

$U$

$U A$

$v$

V

$x$

$y$

Z film thickness parameter

molar concentration

heat capacity rate

specific heat capacity

diffusion coefficient

Wall thickness

gravitational acceleration

mass flow rate per film unit width

specific enthalpy

thermal conductivity

length

mass

molar weight

mass flow rate

Nusselt film thickness parameter

number of transfer units

pressure

heat flux

Reynolds number

area

time

temperature

specific internal energy

total internal energy

overall heat transfer coefficient

velocity

volume

LiBr mass fraction

film coordinate in the thickness direction

liquid level

-
$\mathrm{mol} \cdot \mathrm{m}^{-3}$
$\mathrm{~W} \cdot \mathrm{K}^{-1}$
$\mathrm{~J} \cdot \mathrm{kg}^{-1} \cdot \mathrm{K}^{-1}$
$\mathrm{~m}^{2} \cdot \mathrm{s}^{-1}$
$\mathrm{~m}$
$\mathrm{~m} \cdot \mathrm{s}^{-2}$
$\mathrm{~kg} \cdot \mathrm{s}^{-1} \cdot \mathrm{m}^{-1}$
$\mathrm{~J} \cdot \mathrm{kg}^{-1}$
$\mathrm{~W} \cdot \mathrm{m}^{-1} \cdot \mathrm{K}^{-1}$
$\mathrm{~m}$
$\mathrm{~kg}$
$\mathrm{~g} \cdot \mathrm{mol}^{-1}$
$\mathrm{~kg} \cdot \mathrm{s}^{-1}$
-
-
$\mathrm{kPa}$
$\mathrm{W} \cdot \mathrm{m}^{-2}$
-
$\mathrm{W} \cdot \mathrm{m}^{-2} \cdot \mathrm{K}^{-1}$
$\mathrm{~m} \cdot \mathrm{s}^{-1}$
$\mathrm{~m}{ }^{3}$
$\mathrm{sg} \cdot \mathrm{m}^{-3}$
$\mathrm{~m}$
${ }^{\circ} \mathrm{C}$

$\mathrm{J} \cdot \mathrm{mg}^{-1}$

$\mathrm{W} \cdot \mathrm{m}^{-2} \cdot \mathrm{K}^{-1}$

$\mathrm{kg} \cdot \mathrm{s}^{-1} \cdot \mathrm{m}^{-2}$

$\mathrm{m}$

Pa.s

$\mathrm{m}^{3} \cdot \mathrm{kg}^{-1}$

$\mathrm{kg} \cdot \mathrm{m}^{-3}$

$\mathrm{S}$

\section{Subscripts}

$0 \quad$ initial value

1 section 1 in desorber (below free surface)

2 section 2 in desorber (above free surface) 
abs absorbed

air outside air

$c \quad$ cold fluid

cw chilled water

$d w c \quad$ dropwise condensation

expo exposure

ext coil external side

film falling film (overall)

flash flash evaporation

$h \quad$ hot fluid

$\mathrm{H}_{2} \mathrm{O} \quad$ water

hw hot water

$i \quad$ film interface

inlet desorber film inlet

inner falling film inner layer

int coil internal side

$l \quad$ liquid

layer film layer index (layer = inner, outer $)$

local local quantity

$\max$ maximal

$\min \quad$ minimal

outer falling film outer layer

$s \quad$ LiBr solution

sat saturation

st steady state

sump desorber sump

surf desorber sump free surface

$v \quad$ vapour

w wall

\section{Superscripts}

$A S \quad$ absorber

$C W \quad$ chilled water HX

DS desorber

EV evaporator

EVAS evaporator-absorber (vapour storage)

$H R$ heat recovery $\mathrm{HX}$

in component inlet

out component outlet

$S C \quad$ solution cooler 


\section{INTRODUCTION}

For air conditioning, choosing to use an absorption chiller instead of a conventional vapour compression system can be particularly interesting for several reasons:

- the energy cost of generating mechanical power to drive the compressor is suppressed;

- the $\mathrm{CO}_{2}$ rejection is reduced accordingly;

- the use of greenhouse gases such as HFC refrigerants is avoided.

The essential condition is the availability of an inexpensive or even free heat source such as waste (or rejected) heat. Several studies have been made using solar energy [1,2].

Absorption cooling is based on the strong chemical affinity between two working fluids - the refrigerant and the absorbent - the former having a much lower vapour pressure than the latter. In a single-effect absorption chiller, at the lower pressure and temperature level, the refrigerant is evaporated using the heat removed from the conditioned space and absorbed by the absorbent solution. At the higher pressure and temperature level, a heat source provides the energy needed to extract the absorbed refrigerant vapour from the solution, which is thus regenerated and ready for the next cycle. Water as refrigerant / lithium-bromide as absorbent is one of the most used working fluid pairs in current absorption chillers.

As in other industrial fields, numerical simulation is a powerful and essential tool at every step of the development of new absorption chillers: elemental design and sizing, performance prediction and rating, elaboration of control strategies and understanding of the system behaviour. Whereas steady-state simulations are relatively straightforward and widely used [3], dynamic modelling is more complex, sparse, and still remains a research topic. Yet, the chiller time-dependant response to events such as ambient conditions changes, set point modifications, available power variations, startup and shutdown, periodic on-off operation can only be studied by means of transient simulations. 
One of the earliest dynamic simulations of absorption refrigeration systems has been performed by Jeong et al. [4] for a steam-driven heat pump. The model assumes solution mass storage in the vessels, thermal capacity heat storage, and flow rates (vapour and solution) are calculated according to the pressure differences between vessels. Later, $\mathrm{Fu}$ et al. [5] developed a library of elemental dynamic models for absorption refrigeration systems (CHP applications), in which the components are described as lumped processes involving twophase equilibriums. In a series of two papers, Kohlenbach \& Ziegler [6,7] presented a simulation model and its experimental verification for a single-effect water/LiBr chiller. As a special feature, all thermal capacities have been divided into an external part (influenced by the temperature of the external heat carriers) and an internal part (influenced by the temperature of the refrigerant or the absorbent). Moreover, a transport delay time has been assumed in the solution cycle. Matsushima et al. [8] developed a program using objectoriented formulation and parallel processing to simulate the transient operation of a tripleeffect absorption chiller. A special algorithm based on the pressure difference and flow resistance between the generators and the absorber has been used to calculate the flow rate of solution.

The objective of the present work is to develop a dynamic model for the simulation of a newly designed $15 \mathrm{~kW}$ single-effect water/LiBr absorption chiller. The machine is driven by two distinct heat sources (a main one using waste heat and an auxiliary one), includes an integrated falling film evaporator-absorber, uses mixed recirculation for both the refrigerant and the absorbent solution, and is exclusively cooled thanks to the ambient air. This configuration allows to optimize the size of the system and to reduce the risk of crystallization. In contrast to previous works, the focus is set on the detailed physical modelling of the heat and mass transfer phenomena occurring in the evaporator-absorber and in the desorber. Hence, they can be related to intrinsic features of the components, such as 
their geometrical characteristics. The purpose of this approach is to reduce the model dependence on empirical and global parameters.

After a brief overview of the chiller working principles, the approach used to describe the falling film is introduced and applied to model the evaporator-absorber and desorber. Then, the modelling of the other components and the numerical implementation are discussed. The chiller behaviour under simple changes of input parameters is finally investigated using the resulting overall model: response to a step drop of the heat recovery circuit flow rate, and response to a step drop of the chilled water temperature returning from the conditioned space. In this last case, a basic temperature regulation law is introduced and tested.

\section{MODELLING}

\subsection{Chiller description}

The absorption chiller is shown schematically in Figure 1, with indicative power levels, operation temperatures, and flow rates. Due to confidentiality reasons, the final application will not be discussed in this paper. The chiller is based on a single effect cycle in which water is the refrigerant medium and lithium-bromide is the absorbent medium [9]. It has the particularity of integrating the evaporator and the absorber in a single adiabatic component that needs no cooling from the outside air. In order to optimize the size of the system, high refrigerant and absorbent flow rates are necessary in the evaporator-absorber. Therefore, the cycle is based on two high flow rate recirculation loops (one for the refrigerant and one for the absorbent solution) and a low flow rate regeneration loop. A high absorbent flow rate allows having low lithium-bromide concentration rates in the solution and so avoids crystallization problems. This type of design is well adapted when available space is limited, especially the area exposed to outside air, the only available cooling medium in our application. However, this configuration may produce an electrical over-consumption in the pumps. In the absorbent solution loop, if the pressure drops in pipes are neglected (because of short lengths), the ones 
related to the absorbent solution cooler, where the mass flow rate is equal to $3 \mathrm{~kg} / \mathrm{s}$, are less than $36 \mathrm{kPa}$ (manufacturer's data). In the water loop, they have been estimated at $15 \mathrm{kPa}$ in the chilled water HX. These lead to electric powers of about 200 and $100 \mathrm{~W}$ respectively with pump efficiency of the order of 0.5 .

The working principle of the chiller is as follows. Heat is removed from the conditioned space and transferred to the refrigerant in the chilled water HX. The heated refrigerant then enters the evaporator-absorber. In this unit, a small fraction of the refrigerant inlet flow goes into vapour phase and is absorbed by the strong solution. Hence, latent heat is extracted from the refrigerant and transferred to the absorbent solution. The remaining cooled liquid refrigerant is pumped back to the chilled water HX. Notice that there is no direct contact of the liquid phases in the evaporator-absorber. At the discharge of the circulation pump, the weak solution flow is divided into two circuits. The main part of the flow is cooled down in an air heat exchanger and sent back to the evaporator-absorber (recirculation loop), whereas a small fraction of the flow enters the regeneration loop. In the latter, the solution is preheated close to the desorption temperature in a heat recovery $\mathrm{HX}$, using waste heat from the main source, before entering the desorber. In this unit, powered by an auxiliary heat source, refrigerant vapour is separated from the preheated solution and drawn to the air cooled condenser. The condensate is then reinserted into the refrigerant recirculation loop, whereas the regenerated strong solution is sent back to the absorbent recirculation loop.

\subsection{Absorbent solution film model}

The working principles of the evaporator-absorber and desorber are based on falling film heat and mass transfer. The falling film model used here has been derived from recent works by Auracher et al. [10] and Flessner et al. [11]. Unlike many previous works, (see the review by Killion and Garimella [12]), these models have the distinctive feature of considerably reducing the complexity of the heat and mass transfer coupling, allowing the film problem to 
be solved in a lumped manner. This approach is much more suitable to the simulation of a complete chiller than other more detailed models, in which the number of discretization nodes needed to simulate a single falling film is of an order of magnitude of 100 .

An in-depth description of this modelling approach, including all necessary assumptions and mathematical developments, can be found in [10] and [11]. In the current paper, only the main assumptions and equations are outlined, as the focus is made on its application to our specific components.

\subsubsection{Falling film theory}

Figure 2 schematically shows the geometry of a falling film as well as the temperature and lithium bromide concentration profiles inside the film. First, it is assumed that absorption and desorption only occur during the streaming of the film along the absorption/desorption surface (absorber plates or desorber coil wall): no mass transfer is considered during droplet formation and fall (e.g. between two adjacent turns of the coil). At the inlet and outlet of the film, the fluid is supposed to be well mixed (homogeneous properties). The flow is assumed to be laminar. The geometry of the film is assumed to be straight and one-dimensional. This assumption implies that the possible formation of preferential flow paths (across the width of the absorber plates or across the circumference of the desorber coils) is not taken into account. Under these assumptions, the stagnant film theory of Nusselt can be used to obtain the thickness and velocity of the falling film. The film Reynolds number is expressed as:

$$
R e_{f i m}=\frac{4 \dot{G}}{\eta_{s}}
$$

where $\dot{G}$ is the flow rate per unit width of the film and $\eta_{s}$ is the dynamic viscosity of the solution. Several correlations of the film thickness in terms of the Reynolds number have been proposed for the laminar, wavy-transition and turbulent flow regimes [13]. In many of them, a 
dimensionless film thickness, named the Nusselt film thickness parameter $N_{T}$, is introduced. It is defined as:

$$
N_{T}=\delta_{f i l m}\left(g \frac{\rho_{s}^{2}}{\eta_{s}^{2}}\right)^{1 / 3}
$$

with $\delta_{\text {film }}$ the film thickness, $g$ the gravitational acceleration and $\rho_{s}$ the density of the solution. According to the original Nusselt theory, for the laminar regime, the Nusselt film thickness parameter is linked to the Reynolds number by:

$$
N_{T}=0.909 R e^{1 / 3}
$$

In this work, an alternative correlation, the Brötz equation [13], is used:

$$
N_{T}=0.0682 R e^{2 / 3}
$$

This correlation has been shown to be in excellent agreement with experimental measurements over a wide range of Reynolds numbers, including transitional and turbulent regimes. Indeed, in falling films, even at large Reynolds numbers, a relatively nonturbulent "laminar sublayer" occupies a significant part of the film thickness, whereas wavy or turbulent effects occur mostly in the superficial layer of the film. Hence, the laminar-turbulent transition is not sharply marked, and the use of a correlation valid over a wider range of flow regimes such as Brötz's is more realistic than the basic Nusselt equation (3).

The Nusselt analysis expresses the velocity of the film surface $v_{f i l m}$ as:

$$
v_{f i m}=\frac{3}{2} \frac{\dot{G}}{\rho_{s} \delta_{f i l m}}
$$

Recalling the assumption that steam absorption only occurs at the film surface when the solution is in falling film mode, a time of exposure based on the surface velocity can be defined:

$$
t_{\text {expo }}=\frac{L}{v_{\text {film }}}
$$


where $L$ is the film length. In the evaporator-absorber, the film length is equal to the plate height (Figure 3). In the desorber, the film length is given by the outer half-circumference of the coil tube multiplied by the number of steam-exposed turns (Figure 4).

\subsubsection{Film mass transfer}

As shown in [10], the time of exposure is much smaller than the time needed for the concentration boundary layer to reach the wall. Hence, mass transfer can be regarded as instationary diffusion of water into a semi-infinite body and the concentration profile across the film thickness is given by:

$$
\frac{c_{\mathrm{H}_{2} \mathrm{O}}(y, t)-c_{\mathrm{H}_{2} \mathrm{O}}(y, t=0)}{c_{\mathrm{H}_{2} \mathrm{O}}(y=0, t)-c_{\mathrm{H}_{2} \mathrm{O}}(y, t=0)}=\operatorname{erfc}\left(\frac{y}{2 \sqrt{D \cdot t}}\right)
$$

$c_{\mathrm{H}_{2} \mathrm{O}}$, the molar water concentration of the absorbent solution, is linked to the lithium bromide mass fraction $x_{s}$ by the following relationship:

$$
c_{\mathrm{H}_{2} \mathrm{O}}(y, t)=\frac{\left[1-x_{s}(y, t)\right] \rho_{s}}{\tilde{M}_{\mathrm{H}_{2} \mathrm{O}}}
$$

with $\tilde{M}_{\mathrm{H}_{2} \mathrm{O}}$ the molar weight of water.

The local mass flow rate of absorbed vapour entering the film at a given point of the steam/film interface $(y=0)$ can be expressed by Fick's law:

$$
\dot{m}_{a b s, l o c a l}=-S_{a b s} \tilde{M}_{\mathrm{H}_{2} \mathrm{O}} D\left(\frac{\partial c_{\mathrm{H}_{2} \mathrm{O}}}{\partial y}\right)_{y=0}
$$

where $D$ is the binary diffusion coefficient of water in lithium bromide and $S_{a b s}$ the absorption area. The total vapour mass absorbed by the film between the inlet and the outlet of the absorption surface is obtained by integrating the local mass flow rate over the time of exposure:

$$
m_{a b s}=\int_{0}^{t_{\text {expo }}} \dot{m}_{a b s, l o c a l} d t
$$

Inserting eq. (9) into eq. (10) and combining with eqs. (7) and (8), the absorbed vapour mass eventually reads: 


$$
m_{a b s}=S_{a b s}\left(x_{s}-x_{s_{i}}\right) \rho_{s} \frac{2 \sqrt{D \cdot t_{\text {expo }}}}{\sqrt{\pi}}
$$

$x_{s_{i}}$ denotes the LiBr mass fraction at the film interface, and $x_{s}$ is the $\mathrm{LiBr}$ mass fraction in the bulk of the film. The assumption of ideal mixing at the inlet of the film implies uniform inlet concentration across the film thickness:

$$
x(y, t=0)=x^{i n}
$$

Due to the very small amount of steam absorbed or desorbed during the time of exposure, the bulk concentration $x_{s}$ remains equal to the film inlet concentration. Moreover, the density of the solution in the bulk of the film and at the interface can be considered equal to a mean density $\rho_{s}$ since the change in concentration remains small.

Using Eq. (11), the average absorbed or desorbed mass flow rate for the whole film is then written as:

$$
\dot{m}_{a b s}=\frac{m_{a b s}}{t_{\text {expo }}}=\beta S_{a b s}\left(x_{s}-x_{s_{i}}\right)
$$

where $\beta$ is the mass transfer coefficient:

$$
\beta=\frac{2 \rho_{s}}{\sqrt{\pi}} \sqrt{\frac{D}{t_{\text {expo }}}}
$$

\subsubsection{Film heat transfer}

Absorption and desorption are respectively exothermic and endothermic processes. As steam is absorbed at the film surface, heat of absorption is released and transferred across the film thickness to the wall and the secondary cooling fluid, if any. Conversely, for desorption, the energy brought by the heat source is transferred to the colder surface layer of the film, where vapour is released.

To handle the heat transfer problem in actual chiller components, Flessner et al. [11] have extended the theoretic work by Auracher et al. [10]. In their update, the model becomes 
applicable to subcooled and superheated conditions in the bulk phase of the film. To do so, the film is divided into two layers:

- the outer layer, in contact with the vapour phase, where the heat transfer between the film surface and the core is coupled with the mass transfer of the absorption/desorption process;

- the inner layer, where the heat transfer between the core of the film and the wall is assumed to be independent of the mass transfer occurring at the surface.

In both layers, the temperature profile is assumed to be linear. However, in the outer layer, the temperature gradient is steeper than in the inner layer due to the local release/absorption of latent heat at the film surface. Using Nusselt's theory, heat transfer is calculated separately in each layer. The coupling between the two layers is achieved thanks to the interface temperature $T_{S}$ (see Figure 2). As a first approximation, Flessner et al. [11] constantly set this coupling temperature as the mixed cup temperature at the film outlet $T_{s}^{\text {out }}$, obtained from the energy balance over the whole film. They also assume a distribution of the overall film thickness between the two layers as follows:

$$
\delta_{\text {outer }}=a \delta_{\text {film }}
$$

with the value of $a$ set to 0.1 . Strictly speaking, this constant should be determined from experimental data; however, the value used by Flessner et al. [11] in first approximation is consistent with other works from the literature [14].

Thus, in the outer layer:

$$
\dot{m}_{a b s} \Delta h_{a b s}=\alpha_{\text {outer }} S_{a b s}\left(T_{s_{i}}-T_{s}\right)
$$

with $\Delta h_{a b s}$ the latent heat of absorption and $T_{s_{i}}$ the film surface temperature. It should be noticed that the coupling between heat and mass transfer is ensured in the model by eq. (16). 
In the inner layer, only sensible heat transfer occurs. The heat flux $\dot{Q}_{w}\left(\mathrm{~W} \cdot \mathrm{m}^{-2}\right)$ exchanged with the wall reads:

$$
\dot{Q}_{w}=\alpha_{\text {inner }} S_{a b s}\left(T_{s}-T_{w}\right)
$$

with $T_{w}$ the wall temperature. The heat transfer coefficient across each layer (outer and inner) is:

$$
\alpha_{\text {layer }}=\frac{k_{s}}{\delta_{\text {layer }}}
$$

where $k_{s}$ is the thermal conductivity of the solution. Finally, the equilibrium between the vapour and the liquid phases is assumed to be effective only at the film surface:

$$
T_{s_{i}}=T\left(x_{s_{i}}, p\right)
$$

where $p$ is the pressure at the film surface.

\subsection{Evaporator-absorber}

\subsubsection{Description}

The so-called evaporator-absorber is a custom component, derived from the technology presented in [15]. It has been specifically designed to integrate in a single unit two essential functions usually ensured by two distinctive heat exchangers in conventional absorption chillers:

- the evaporation of liquid refrigerant on the low pressure side (usually ensured by the evaporator);

- the absorption of gaseous refrigerant by the absorbent solution (usually ensured by the absorber).

This type of design is necessitated by the important recirculation rate used in this absorption cycle: only a small fraction of the refrigerant flow is brought to gas phase and absorbed by the lithium bromide solution. The working principle of the evaporator-absorber is illustrated by Figure 3. It is basically constituted of an array of vertical parallel plates enclosed in an airtight 
chamber. Each plate is fed by a horizontal distribution tube located on its top edge. The wall of the tube is drilled, in order to generate a falling film on the entire surface of the plate. The fluid distribution is alternate: refrigerant on the odd plates, strong absorbent solution on the even plates. Hence, a refrigerant falling film is always facing an absorbent falling film. Due to the difference between the refrigerant inlet line pressure and the chamber internal pressure, a fraction of the refrigerant instantly goes into gas phase as soon as it enters the chamber (flash evaporation). Another minim fraction is then evaporated as the saturated liquid streams down the plate (slight pressure loss). Saturated refrigerant vapour accumulates in the evaporatorabsorber chamber until it is absorbed at the surface of the facing lithium bromide solution film. As shown in the falling film modelling section, the absorption rate is dependant on the solution inlet conditions (temperature, concentration) as well as on the falling film kinematics. At the bottom of the plates, both fluids drip in a drainage tray, preventing direct mixing of the liquid phases.

The sizing of the evaporator-absorber (i.e. the number and dimensions of evaporation and absorption plates) ensures that the thermal power removed from the conditioned volume and carried by the refrigerant is transferred to the absorbent solution at a sufficient rate. Thus, through this component, the refrigerant temperature decreases whereas the lithium bromide solution temperature increases.

\subsubsection{Modelling}

The modelling approach used for the evaporator-absorber is illustrated by Figure 5. Four nodes are defined: the refrigerant inlet, the adiabatic chamber, the absorbent solution film and the absorber plate (or "wall"). Mass, energy and species balances are then written for the relevant nodes.

On the refrigerant side, only the flash evaporation is taken into account, as it represents the essential part of the refrigerant phase change. This means that the evaporation caused by 
friction pressure loss along the plates is neglected. The mass and energy balance at the refrigerant inlet read:

$$
\begin{gathered}
\dot{m}^{\text {EVin }}=\dot{m}_{\text {flash }}^{E V}+\dot{m}^{\text {EVout }} \\
\dot{m}^{\text {EVin }} h^{\text {EVin }}=\dot{m}_{\text {flash }}^{E V} h_{\text {flash }}^{E V}+m^{E V o u t} h^{E V o u t}
\end{gathered}
$$

The flashed vapour is saturated vapour and the residual liquid (refrigerant film) leaving the evaporator-absorber is saturated liquid, corresponding to the internal pressure $p^{E V A S}$ :

$$
\begin{aligned}
& h_{\text {flash }}^{E V}=h_{v_{s a t}}\left(p^{E V A S}\right) \\
& h^{E V o u t}=h_{l_{s a t}}\left(p^{E V A S}\right)
\end{aligned}
$$

The adiabatic chamber node is handled as an accumulation node in terms of vapour mass $M^{E V A S}$ and specific internal energy $u^{E V A S}$ :

$$
\begin{gathered}
\frac{d M^{E V A S}}{d t}=\dot{m}_{\text {flash }}^{E V}-\dot{m}_{a b s}^{A S} \\
\frac{d}{d t}\left(M^{E V A S} u^{E V A S}\right)=\dot{m}_{\text {flash }}^{E V} h_{\text {flash }}^{E V}-\dot{m}_{a b s}^{A S} h^{E V A S}
\end{gathered}
$$

where $\dot{m}_{a b s}^{E V}$ is the total mass flow rate of vapour absorbed by the lithium bromide films. $h^{E V A S}$ is the specific enthalpy corresponding to the specific internal energy of the accumulated vapour. The internal pressure is given by an equation of state:

$$
p^{E V A S}=p\left(u^{E V A S}, v^{E V A S}\right)
$$

with $v^{E V A S}$ the specific volume of the refrigerant vapour, calculated on the basis of the total vapour mass present in the chamber (the total free volume being $V^{E V A S}$ ):

$$
v^{E V A S}=\frac{V^{E V A S}}{M^{E V A S}}
$$

For the absorbent film node, the total mass balance (Eq. (28)), the lithium bromide mass balance (Eq. (29)) and the energy balance (Eq. (30)) are written. No mass storage in the liquid 
phase is assumed, but the energy balance is instationary to account for heat storage in the control volume:

$$
\begin{gathered}
\dot{m}_{s}^{A S \text { Sin }}+\dot{m}_{a b s}^{A S}-\dot{m}_{s}^{A S o u t}=0 \\
\dot{m}_{s}^{A S i n} x^{A S i n}-\dot{m}_{s}^{A S o u t} x^{A S o u t}=0 \\
\frac{d U_{s}^{A S}}{d t}=\dot{m}_{s}^{A S i n} h_{s}^{A S i n}-\dot{m}_{s}^{A S o u t} h_{s}^{A S o u t}+\dot{m}_{a b s}^{A S} h^{E V A S}+\dot{Q}_{w}^{A S}
\end{gathered}
$$

The absorption mass flow rate $\dot{m}_{a b s}^{A S}$ and the heat flux transferred to the plate $\dot{Q}_{w}^{A S}$ are calculated according to the film modelling approach developed in section 2.2. In particular, Eqs. (13), (16) and (17) become:

$$
\begin{gathered}
\dot{m}_{a b s}^{A S}=\beta^{A S} S_{a b s}^{A S}\left(x^{A S i n}-x_{i}^{A S}\right) \\
\dot{m}_{a b s}^{A S} \Delta h_{a b s}=\alpha_{o u t e r}^{A S} S_{a b s}^{A S}\left(T_{s_{i}}^{A S}-T_{s}^{A S o u t}\right) \\
\dot{Q}_{w}^{A S}=\alpha_{\text {inner }}^{A S} S_{a b s}^{A S}\left(T_{s}^{A S \text { out }}-T_{w}^{A S}\right)
\end{gathered}
$$

with the film surface temperature $T_{s_{i}}^{A S}$ being the equilibrium temperature of the LiBr solution at concentration $x_{i}^{A S}$ and pressure $p^{E V A S}$.

Finally, an instationary energy balance is also considered for the wall node:

$$
\frac{d T_{w}^{A S}}{d t}=\frac{\dot{Q}_{w}^{A S}}{M_{w}^{A S} C p_{w}^{A S}}
$$

where $M_{w}^{A S}$ is the total mass of absorption plates and $C p_{w}^{A S}$ is the heat capacity of the material composing the plates.

\subsection{Desorber}

\subsubsection{Description}

The function of the desorber (or generator) is to separate the refrigerant (water) from the absorbent solution in the regeneration loop. It consists in a cylindrical vertical vessel containing two concentric vertical coils acting as heat transfer surfaces (Figure 4). After being 
pumped through the recovery heat exchanger, the preheated weak solution enters the vessel and feeds a circular distributor located over the coils. A falling film is thus created on the walls of the coil tubes, whereas hot water from an auxiliary heat source is circulated inside the coils. Hence, heat is transferred from the hot water to the absorbent solution film surface, where steam is desorbed. At the top of the vessel, an outlet port allows steam to be sent to the condenser.

At the bottom of the vessel, the strong solution outlet port is connected to the pump suction line. If the outlet flow rate is smaller than the falling film flow rate, absorbent solution accumulates in the solution sump. The lower portion of the coil is then immersed in the liquid (section 1), resulting in much lower heat and mass transfer coefficients than in the falling film mode (section 2). This means that the desorption rate is dependant on the level of liquid $Z^{D S}$ in the vessel. In order to express the ratio between section 1 and section 2 , a dimensionless liquid level is defined as:

$$
Z^{* D S}=\frac{Z^{D S}}{Z_{\max }^{D S}}
$$

where $Z_{\max }^{D S}$ is the maximal height of liquid in the vessel.

\subsubsection{Modelling}

In this component, steam generation is modelled according to three successive processes:

- $\quad$ setting up of equilibrium of the preheated solution at the desorber inlet;

- falling film desorption on the heated coils (section 2);

- desorption from the solution sump at the bottom of the vessel (section 1).

Eight nodes are used to describe the desorber. They are represented on Figure 6 with the relevant mass and energy fluxes. It is assumed that at the exit of the recovery heat exchanger, the absorbent solution is not at equilibrium and remains in the liquid phase (subcooled liquid). As soon as the solution enters the desorber, the equilibrium corresponding to the internal 
pressure $p^{D S}$ is reached, and some vapour is separated from the solution. For the solution inlet node, the total mass balance, $\mathrm{LiBr}$ mass balance and energy balance are expressed by Eqs. (36) to (38):

$$
\begin{gathered}
\dot{m}_{s}^{D S i n}-\dot{m}_{s, \text { inlet }}^{D S}-\dot{m}_{v, \text { inlet }}^{D S}=0 \\
\dot{m}_{s}^{D S i n} x^{D S i n}-\dot{m}_{s, \text { inlet }}^{D S} x_{\text {inlet }}^{D S}=0 \\
\dot{m}_{s}^{D S i n} h_{s}^{D S \text { in }}-\dot{m}_{s, \text { inlet }}^{D S} h_{s, \text { inlet }}^{D S}-\dot{m}_{v, \text { inlet }}^{D S} h_{v, \text { inlet }}^{D S}=0
\end{gathered}
$$

Again, the falling film desorption on the coils is modelled following the approach presented in section 2.2. In this specific case, Eqs. (13), (16) and (17) become:

$$
\begin{gathered}
\dot{m}_{v, \text { film }}^{D S}=\beta^{D S} S_{\text {ext }}^{D S}\left(1-Z^{* D S}\right)\left(x_{\text {inlet }}^{D S}-x_{i}^{D S}\right) \\
\dot{m}_{v, \text { film }}^{D S} \Delta h_{a b s}=\alpha_{\text {outer }, 2}^{D S} S_{\text {ext }}^{D S}\left(1-Z^{* D S}\right)\left(T_{i}^{D S}-T_{s, \text { film }}^{D S}\right) \\
\dot{Q}_{w, 2}^{D S}=\alpha_{\text {inner }, 2}^{D S} S_{\text {ext }}^{D S}\left(1-Z^{* D S}\right)\left(T_{s, \text { film }}^{D S}-T_{w, 2}^{D S}\right)
\end{gathered}
$$

with the film surface temperature $T_{i}^{D S}$ being the equilibrium temperature of the LiBr solution at concentration $x_{i}^{D S}$ and pressure $p^{D S}$.

In order to minimize the number of differential equations in the chiller global model, the whole exposed portion of the coil (section 2) is handled as a single node, representing a single film. Since only energy can be stored in the film, the balance equations read:

$$
\begin{gathered}
\dot{m}_{s, \text { inlet }}^{D S}-\dot{m}_{s, \text { film }}^{D S}-\dot{m}_{v, \text { film }}^{D S}=0 \\
\dot{m}_{s, \text { inlet }}^{D S} x_{\text {inlet }}^{D S}-\dot{m}_{s, \text { film }}^{D S} x_{\text {film }}^{D S}=0 \\
\frac{d U_{s, \text { film }}^{D S}=\dot{m}_{s, \text { inlet }}^{D S} h_{s, \text { inlet }}^{D S}-\dot{m}_{s, \text { film }}^{D S} h_{s, \text { film }}^{D S}-\dot{m}_{v, \text { film }}^{D S} h_{v, \text { film }}^{D S}+\dot{Q}_{w, 2}^{D S}}{d t}
\end{gathered}
$$

On the contrary, in the solution sump, both mass and energy can be stored. The solution is heated by the immersed section of the coils. Perfect mixing is assumed: the properties of the 
solution leaving the desorber by the outlet port are equal to that of the solution sump. The total mass, LiBr mass and energy balances are expressed by Eqs. (45) to (47).

$$
\begin{gathered}
\frac{d M_{s, \text { sump }}^{D S}}{d t}=\dot{m}_{s, \text { film }}^{D S}-\dot{m}_{s}^{D S o u t}-\dot{m}_{v, \text { sump }}^{D S} \\
\frac{d M_{L i B r, \text { sump }}^{D S}}{d t}=\dot{m}_{s, \text { film }}^{D S} x_{\text {film }}^{D S}-\dot{m}_{s}^{D S o u t} x^{D S o u t} \\
\frac{d U_{s, \text { sump }}^{D S}}{d t}=\dot{m}_{s, \text { film }}^{D S} h_{s, \text { film }}^{D S}-\dot{m}_{s}^{D S o u t} h_{s}^{D S o u t}-\dot{m}_{v, \text { sump }}^{D S} h_{v, \text { sump }}^{D S}+\dot{Q}_{w, 1}^{D S}
\end{gathered}
$$

One should note that for all desorption processes, the enthalpy of desorbed vapour is equal to the enthalpy of super heated vapour at pressure $p^{D S}$ and temperature $T_{S}^{D S o u t}$ :

$$
h_{v}^{D S}=h_{v}\left(p^{D S}, T_{S}^{D S o u t}\right)
$$

The overall desorbed vapour flow rate leaving the desorber and sent to the condenser is the algebraic sum of the individual vapour flow rates generated in the three successive processes:

$$
\dot{m}_{v}^{D S o u t}=\dot{m}_{v, \text { inlet }}^{D S}+\dot{m}_{v, \text { film }}^{D S}+\dot{m}_{v, \text { sump }}^{D S}
$$

Heat is transferred from the hot water to the $\mathrm{LiBr}$ solution through the coil tube. Energy storage in the walls is taken into account by Eqs. (50) and (51) (respectively section 1 and 2):

$$
\begin{gathered}
\frac{d T_{w, 1}^{D S}}{d t}=\frac{1}{M_{w}^{D S} Z^{* D S} C p_{w}^{D S}}\left(\dot{Q}_{h w, 1}^{D S}-\dot{Q}_{w, 1}^{D S}\right) \\
\frac{d T_{w, 2}^{D S}}{d t}=\frac{1}{M_{w}^{D S}\left(1-Z^{* D S}\right) C p_{w}^{D S}}\left(\dot{Q}_{h w, 2}^{D S}-\dot{Q}_{w, 2}^{D S}\right)
\end{gathered}
$$

with the heat fluxes on the solution side expressed as:

$$
\begin{gathered}
\dot{Q}_{w, 1}^{D S}=\alpha_{e x t, 1}^{D S} S_{e x t}^{D S} Z^{* D S}\left(T_{w, 1}^{D S}-T_{s, s u m p}^{D S}\right) \\
\dot{Q}_{w, 2}^{D S}=\alpha_{e x t, 2}^{D S} S_{e x t}^{D S}\left(1-Z^{* D S}\right)\left(T_{w, 2}^{D S}-T_{s, f i l m}^{D S}\right)
\end{gathered}
$$

Note that in section 2, the external heat transfer between the wall and the solution film is governed by the heat transfer coefficient of the film inner layer: 


$$
\alpha_{\text {ext }, 2}^{D S}=\alpha_{\text {inner }}^{D S}
$$

and calculated using Eq. (18).

No energy storage is assumed for the hot water circulating in the coils. The energy balance is respectively, for section 1 and section 2:

$$
\begin{gathered}
\dot{m}_{h w}^{D S}\left(h_{h w, s u r f}^{D S}-h_{h w}^{D S i n}\right)=-\dot{Q}_{h w, 1}^{D S} \\
\dot{m}_{h w}^{D S}\left(h_{h w}^{D S o u t}-h_{h w, s u r f}^{D S}\right)=-\dot{Q}_{h w, 2}^{D S}
\end{gathered}
$$

The heat fluxes on the hot water side are calculated according to Eqs. (57) and (58):

$$
\begin{gathered}
\dot{Q}_{h w, 1}^{D S}=\alpha_{\mathrm{int}}^{D S} S_{\mathrm{int}}^{D S} Z^{* D S}\left(T_{h w, 1}^{D S}-T_{w, 1}^{D S}\right) \\
\dot{Q}_{h w, 2}^{D S}=\alpha_{\mathrm{int}}^{D S} S_{\mathrm{int}}^{D S}\left(1-Z^{* D S}\right)\left(T_{h w, 2}^{D S}-T_{w, 2}^{D S}\right)
\end{gathered}
$$

where the water temperatures $T_{h w, 1}^{D S}$ and $T_{h w, 2}^{D S}$ are the average between the inlet or outlet temperature $\left(T_{h w}^{D S i n}\right.$ or $\left.T_{h w}^{D S o u t}\right)$ and the hot water temperature at the level of the solution free surface $T_{h w, \text { surf }}^{D S}$.

\subsection{Single phase heat exchangers}

In the framework of a complete chiller simulation, true transient distributed models of the heat exchangers based on finite volume discretization are not suitable because of the high number of nodes required to simulate complex flow arrangements. In this work, the three single phase heat exchangers (chilled water HX, solution cooler and heat recovery HX) are modelled using a pseudo-transient approach. The time-dependant outlet temperature is assumed to follow a first-order evolution from the initial outlet temperature value $T_{0}^{\text {out }}$ to the steady-state temperature value $T_{s t}^{\text {out }}$ :

$$
T^{\text {out }}(t)=T_{0}^{\text {out }}+\frac{1}{\tau} \int_{0}^{t}\left(T_{s t}^{\text {out }}-T^{\text {out }}(t)\right) d t
$$


It is important to notice that the steady-state outlet temperature is re-evaluated at each time step of the simulation. The time constant $\tau$ can be determined either experimentally or using a detailed distributed transient model of the heat exchanger. To do so, the heat exchanger is simulated independently of the others components, with imposed inlet conditions. Starting from steady-state, a step in inlet temperature or enthalpy is imposed and the stabilization time (i.e. the time necessary to reach the new steady-state) is determined. The time constant is adjusted until the stabilization time in the pseudo-transient model matches that of the detailed transient model (or the experimental data). As the response is assumed to be of the first order type, the shape of the pseudo-transient temperature evolution generally differs from the true transient one. However, the most representative feature of a heat exchanger dynamics is its time constant, and the use of the pseudo-transient approach leads to sufficiently accurate results regarding the global chiller dynamics.

The NTU-effectiveness method is used to calculate the steady-state outlet temperatures as functions of the inlet temperatures, the heat capacity rates of the hot and cold fluid, and the heat exchanger effectiveness $\varepsilon$ :

$$
T_{s t_{h, c}}^{o u t}=T_{h, c}^{i n}+\chi \varepsilon \frac{C_{\min }}{C_{h, c}}\left(T_{h}^{i n}-T_{c}^{i n}\right)
$$

with $C_{\min }=\min \left(C_{h}, C_{c}\right), \chi=1$ for the cold fluid and $\chi=-1$ for the hot fluid. If needed, an analogous expression using specific enthalpies instead of temperatures for either the hot or the cold fluid (or even for both fluids) can be derived.

The effectiveness is linked to the number of transfer units (NTU) and the heat capacity rates by a function $f$ that depends on the configuration of the heat exchanger (see for example [16]):

$$
\varepsilon=f\left(N T U, C_{h}, C_{c}\right)
$$

The number of transfer units is defined as the ratio of the overall heat transfer coefficient to the minimum heat capacity rate: 


$$
N T U=\frac{U A}{C_{\min }}
$$

The overall heat transfer coefficient takes into account the local heat transfer coefficients and the heat transfer surfaces on the hot and cold fluid sides, as well as the conduction heat transfer across the walls:

$$
U A=\left[\frac{1}{\alpha_{h} S_{h}}+\frac{1}{\alpha_{c} S_{c}}+\frac{e_{w}}{k_{w} S_{w}}\right]^{-1}
$$

The main characteristics of the heat exchangers, including the references of the correlations used to evaluate the local heat transfer coefficients, are given in tables 1,2 and 3.

\subsection{Condenser}

\subsubsection{3-zone model}

The pseudo-transient approach used for the single phase heat exchangers is also suitable to model heat transfer in the condenser. However, in this particular heat exchanger, the refrigerant is subjected to phase change: it enters as superheated vapour and exits as subcooled liquid. Therefore, Eqs. (59) and (60) are formulated with enthalpies instead of temperatures, and the condenser is divided into three distinct sections: the de-superheating section, the two-phase section and the subcooling section. A fraction of the total heat transfer area is affected to each section. The refrigerant is treated as a homogeneous fluid. The main characteristics of the condenser are summarized in table 4.

The distribution of the section areas is not known beforehand, but the state of the fluid at the section boundaries does. The refrigerant generally enters the condenser in the superheated vapour state, with a known specific enthalpy. The de-superheating section being defined as the area necessary for the refrigerant to reach the saturated vapour state, the enthalpy reduction associated to this section is known. This allows determining successively the corresponding effectiveness, NTU and heat transfer area necessary to achieve this enthalpy reduction, according to the method presented in section 2.5. The same methodology is applied 
for the determination of the two-phase section heat transfer area, knowing that the refrigerant enters this section at saturated vapour state and exits at saturated liquid state. Finally, the subcooling section area can be calculated as the difference between the total heat transfer area and the sum of the two previous section areas. The corresponding NTU and effectiveness are then determined, which yields the outlet enthalpy of the condensate.

If the total available heat transfer area is too small to ensure that the refrigerant reaches the saturated liquid state, the condenser outlet state is two-phase and there is no subcooling section. The outlet vapour quality of the refrigerant is then evaluated as a function of the outlet enthalpy and condensation pressure.

\subsubsection{Condensation pressure}

The pressure at the condenser is assumed to be determined by the pressure in the refrigerant bottle receiving the condensate. Mass and internal energy storage in the bottle are described by transient balance equations, and the equilibrium condition (saturated liquid state in the bottle) yields the bottle pressure.

\subsubsection{Condensation heat transfer coefficient}

Due to the low refrigerant mass flow rate in the condenser copper tubes, the maximum Reynolds number of the condensate flow is approximately 15. Using the Nusselt laminar film analysis, the thickness of the corresponding refrigerant film inside the tubes would be inferior to $35 \mu \mathrm{m}$. Moreover, the wettability of copper is rather low. Consequently, dropwise condensation is the most likely to occur. Griffith [19] has proposed the following correlation to estimate the heat transfer coefficient $\alpha_{d w c}$ in dropwise condensation (unit: $\mathrm{kW} \cdot \mathrm{m}^{-2} \cdot \mathrm{K}^{-1}$ ):

$$
\alpha_{d w c}=51.1+2.04 T_{s a t}
$$

This relationship is valid for $22^{\circ} \mathrm{C}<T_{\text {sat }}<100{ }^{\circ} \mathrm{C}$. 


\subsection{Numerical implementation}

The equation solver EES has been used to handle the resulting global model. To set up the global chiller model, all the individual component sets of equations have been linked together using internal variables, and the initial and external conditions have been specified. The fluid properties (water and lithium-bromide solution) are available in libraries included in the EES software. The results presented in this paper have been obtained using a constant simulation time step of $1 \mathrm{~s}$.

\section{APPLICATION}

The model consistency and dynamic behaviour can be analyzed by applying a step change to one of the external parameters, which are of three kinds: the hot water inlet parameters (heat recovery), the outside air parameters (ambient conditions), and the chilled water inlet parameters (thermal load).

First, the simulation is started using the input parameters summarized in table 5. The steady state corresponding to these input parameters is reached after approximately $300 \mathrm{~s}$. It should be noticed that the choice of the initial values (for differential equations) is arbitrary and has no effect on the steady state. Then, at $t=500 \mathrm{~s}$, a step change on one of the external control parameters is imposed, while all the other parameters remain unmodified. The system reacts to this parameter change and a new steady state is reached after a transient period.

\subsection{Response to a reduction of the hot water flow rate in the heat recovery $\mathbf{H X}$}

This case is intended to simulate a drop in heat recovery fluid flow rate, which occurs frequently when the hot fluid circulation pump is directly coupled to a variable speed engine as, for example, in internal combustion engines. Here, the initial flow rate $\dot{m}_{h w}^{H R}$ is reduced at $t$ $=500 \mathrm{~s}$ from $0.5 \mathrm{~kg} / \mathrm{s}$ to $0.17 \mathrm{~kg} / \mathrm{s}$ (approximately divided by 3 ). 
Since less energy is brought to the heat recovery HX, the enthalpy of the absorbent solution leaving this exchanger instantly decreases (Figure 7a) and the vapour flow rate generated as the solution enters the desorber decreases as well (Figure 7d) (“desorber inlet" node). This is also noticeable on the concentration diagram (Figure 7e), where the gap between the recovery HX concentration and the desorber inlet concentration starts to reduce. As a consequence, the total vapour flow rate leaving the desorber and sent to the condenser firstly drops, and the concentration of the strong regenerated solution is reduced, since less refrigerant is extracted. The regenerated solution then returns to the solution pump suction, where it mixes with the recirculation loop solution, inducing a general decrease of the concentrations and solution enthalpies in the chiller. The concentration reduction of the solution leads to a decrease of its absorption potential. Therefore, in the evaporator-absorber, the vapour flow rate from the refrigerant to the solution starts to decline (Figure 7d), and so does the heat flux (Figure 7h). This corresponds to a reduction in the frigorific effect: the enthalpy and the temperature of the refrigerant leaving the evaporator-absorber and entering the chilled water HX increase (Figure $7 \mathrm{~b}$ and Figure $7 \mathrm{~g}$ ), leading to a rise of the chilled water temperature and a decrease in the chilled water HX heat flux representing the frigorific power of the system (Figure 7i).

Since less vapour is desorbed, the thermal load of the condenser is reduced. Therefore, the degree of subcooling of the condensate increases, so its enthalpy (Figure $7 \mathrm{~b}$ ) and its temperature (Figure 7f) fall dramatically. In the condensate bottle, this temperature drop is noticeable, though very attenuated by the damping effect of the stored refrigerant mass. The liquid-vapour equilibrium in the condensate bottle is therefore modified, and the equilibrium pressure is lowered. Since in our model, the condensation pressure and the desorber internal pressure are directly linked to the condensate bottle pressure and vary alike, the liquid-vapour equilibrium in the desorber is also modified (Figure 7c). Indeed, a reduction of the desorber pressure level induces a reduction of the refrigerant evaporation temperature, which leads to 
an enhancement of the desorption process. This is obvious on Figure $7 \mathrm{~d}$ : the vapour flow rates from the desorber film and sump start to increase. On Figure 7e, this results in an increase in the gap between the desorber inlet and outlet concentrations. As a result, the decreasing total vapour mass flow rate produced by the desorber and sent to the condenser reaches a minimum, then starts to re-increase and stabilizes at its steady-state value as the new liquidvapour equilibrium is set in the desorber (Figure $7 \mathrm{~d}$ ). The condenser response follows a similar evolution: since the refrigerant vapour flow rate (i.e. the thermal duty of the exchanger) re-increases, the degree of subcooling of the refrigerant decreases and its outlet temperature and enthalpy rise again.

Basically, the evaporator-absorber and the desorber-condenser ensemble behave like selfregulated systems: if the vapour production is enhanced, their internal pressure increases, which tends to shift the liquid-vapour equilibrium in a way that penalizes and stabilizes the desorption rate. Conversely, if the desorption rate decreases, the internal pressure of the vessels falls and the new equilibrium tends to promote vapour production.

In the present example, the desorption pressure reduction allows the desorber to partially compensate the power drop in the recovery heat exchanger by an increase in the film and sump desorption rates. Indeed, this effect is accompanied by an increasing heat flux from the auxiliary hot water circuit to the absorbent solution through the desorber coil (at constant auxiliary hot water flow rate and inlet temperature). From the initial steady state to the new steady state, the heat recovery flux drops from 20.6 to $15.8 \mathrm{~kW}(-4.8 \mathrm{~kW})$ whereas the desorber heat flux rises from 13.1 to $15.3 \mathrm{~kW}(+2.2 \mathrm{~kW})$. Thus, the total heat supply reduces from 33.6 to $31.1 \mathrm{~kW}(-2.6 \mathrm{~kW})$ and the frigorific power decreases from 14.2 to $13.0 \mathrm{~kW}(-$ $1.2 \mathrm{~kW})$. Eventually, this results in an outlet chilled water warming of barely $+0.5^{\circ} \mathrm{C}(9.6$ to $\left.10.1^{\circ} \mathrm{C}\right)$ 
In terms of dynamic behaviour, the time necessary for the system to reach the new steady state after the heat recovery flow rate change is approximately $100 \mathrm{~s}$. This time is likely to be underestimated, as no transport delays have been included in the model: as a first approximation, the time needed for the solution and refrigerant to convey any state changes through the circuit has not been taken into account. However, the emphasis has been put on modelling the physical phenomena occurring in the falling film based components (i.e. the evaporator-absorber and the desorber), whereas the dynamics of the other heat exchangers have been implemented rather coarsely.

\subsection{Response to a reduction of the chilled water inlet temperature}

This case attempts to simulate the chiller response to a sudden reduction of cooling demand of the conditioned space air. Indeed, the heat flux entering the chilled water in the air handling units drops, inducing a decrease in its temperature as it is sent back to the chiller. It is clear that the step change represents an extreme solicitation unlikely to occur in normal operation conditions. However, as the aim of this simulation is to highlight the trends of the dynamic behaviour of the system, a simple and instantaneous perturbation have been chosen. In opposition to the previous simulation case, the system is thermostated: the hot water flow rate powering the main recovery heat exchanger is kept constant, but the hot water flow rate supplying energy to the desorber (auxiliary circuit) is controlled according to the chilled water outlet temperature:

$$
\begin{aligned}
& T_{c w}^{C \text { Wout }}<T_{\min }: \quad \dot{m}_{h w}^{D S}=\dot{m}_{\text {min }} \\
& T_{\text {min }} \leq T_{c w}^{C \text { Wout }} \leq T_{\text {max }}: \quad \dot{m}_{h w}^{D S}=\dot{m}_{\text {min }}+\left(\frac{\dot{m}_{\max }-\dot{m}_{\min }}{T_{\max }-T_{\min }}\right)\left(T_{c w}^{C \text { Wout }}-T_{\text {min }}\right) \\
& T_{c w}^{C W o u t}>T_{\max }: \quad \dot{m}_{h w}^{D S}=\dot{m}_{\max }
\end{aligned}
$$

Between the temperature thresholds $T_{\min }$ and $T_{\max }$, the hot water flow rate (i.e. the thermostat opening) is a linear function of the chilled water outlet temperature. The minimal and 
maximal values of the hot water flow rate are respectively $0.001 \mathrm{~kg} / \mathrm{s}$ and $0.5 \mathrm{~kg} / \mathrm{s}$. Those of the chilled water outlet temperature are respectively $9.5^{\circ} \mathrm{C}$ and $10.5^{\circ} \mathrm{C}$.

The evolution of some internal variables is shown on Figure 8. The initial chilled water inlet temperature is set at $16^{\circ} \mathrm{C}$ and all the other input parameters are those of table 5 . With these parameters, the chilled water outlet temperature stabilizes at $10.45^{\circ} \mathrm{C}$, i.e. slightly below the upper threshold of the thermostat, and the corresponding auxiliary hot water flow rate is 0.48 $\mathrm{kg} / \mathrm{s}$. The generated frigorific power is then $14.8 \mathrm{~kW}$. For the initial conditions, the mass and heat transfer coefficients in the lithium bromide film are equal to $0.15 \mathrm{~kg} \cdot \mathrm{m}^{-2} \cdot \mathrm{s}^{-1}$ and $1980 \mathrm{~W} \cdot \mathrm{m}^{-2} \cdot \mathrm{K}^{-1}$ respectively.

The steady state being reached, at $t=500 \mathrm{~s}$, the chilled water inlet temperature is lowered to $13{ }^{\circ} \mathrm{C}$ (Figure 8a). As a result, the chilled water outlet temperature instantly falls under the thermostat lower threshold (down to $9^{\circ} \mathrm{C}$ ), resulting in a drop of the desorber hot water flow rate to the minimal value (Figure $8 \mathrm{~b}$ ). Consequently, the vapour flow rate generated thanks to the desorber coils (i.e. film desorption and sump desorption) drops as well. The desorber heat flux falls from $14 \mathrm{~kW}$ to $1.7 \mathrm{~kW}$. The overall desorbed vapour flow rate being balanced by the absorbed vapour flow rate, the evaporator-absorber heat flux also drops.

Since the overall vapour flow rate decreases, the refrigerant condensation heat flux (Figure 8f) and temperature decrease, and the desorption pressure (related to the condensation pressure) declines (Figure 8d). Thus, because of the new liquid-vapour equilibrium in the desorber, the desorption potential of the preheated solution is enhanced: at the desorber inlet, the vapour flow rate caused by the preheating of the solution in the recovery heat exchanger starts to increase (Figure 8c). Moreover, the desorption temperature is lowered and the strong solution leaving the desorber and returning to the circuit becomes colder: as a result, the heat flux in the heat recovery HX increases and the heat flux in the solution cooler decreases (Figure 8f). 
The hot water flow rate in the desorber coil remains at its minimal value for about $10 \mathrm{~s}$, allowing the chilled water temperature to re-increase over the lower limit and the thermostat to re-open. The thermostat opening then starts to oscillate in a damped way with the chilled water temperature, until the latter eventually stabilizes at the lower limit of $9.5{ }^{\circ} \mathrm{C}$. The oscillation period is approximately $12 \mathrm{~s}$. The observed physical oscillations are linked to the choice of the temperature control. Another type of regulation could result in lower oscillations. It can be noticed that all the variables represented on Figure 8 show oscillations, except the pressure. Indeed, the desorber internal pressure is governed by the internal pressure of the condensate bottle, itself determined by the temperature of the stored condensate. Reminding that perfect mixing is assumed for all mass storages, the refrigerant temperature in the bottle is practically not sensitive to the oscillations of the incoming condensate temperature. Moreover, the time needed to stabilize the bottle temperature affects the desorption pressure evolution, and consequently, the evolution of the desorption rates. This time obviously depends on the amount of refrigerant stored in the bottle. In the present simulation, the bottle is filled with nearly $2 \mathrm{~kg}$, and the desorption pressure reaches steady state after approximately $300 \mathrm{~s}$.

\section{CONCLUSION}

In this paper, a model able to simulate the dynamic behaviour of a special absorption chiller is presented. In the desorber and the evaporator-absorber, the lithium bromide solution falling films are described in a lumped manner by a simple physical approach based on Nusselt's theory. As opposed to a standard approach based on empirical parameters, this formulation links the absorption/desorption rates to the film geometrical characteristics, i.e. to the design parameters of the heat transfer surfaces. Transient balances accounting for mass and heat storage are considered for both components. Other heat exchangers are modelled according to the NUT-effectiveness method coupled with a time constant. The resulting global model is 
used to investigate the dynamic response of the chiller to external conditions variations: step change in the hot water flow rate sent to the main recovery heat exchanger, and step change in the inlet temperature of the chilled water, (i.e. a drop of the chiller thermal load). A simple temperature regulation law has been implemented in the latter case. Both studied cases show that the model is able to simulate the detailed performance of the chiller with good consistency. The response of the system to basic input parameters changes appears to be qualitatively realistic, even if the time constants are probably underestimated since the transport delays of the solutions through the piping have not been taken into account. However, the detailed physical modelling of the falling film enables a clear understanding of the desorber and evaporator-absorber responses to various condition changes, and in particular, their self-regulated behaviour linked to the control of the condensation and evaporation pressures. Next steps of this work include model validation against experimental measurements and implementation of more accurate dynamics for solution transport and heat exchangers transient responses.

\section{Acknowledgements}

This work was made within the framework of a French project of the cluster Lyon Urban Truck and Bus named "CLIMAIRIS" supported by the General Directorate for Enterprise (DGE).

\section{References}

[1] Z.F. Li, K. Sumathy, Simulation of a solar absorption air conditioning system, Energy Convers. Manag. 42 (2001) 313-327.

[2] H. Liu, K.E. N'Tsoukpoe, N. Le Pierres, L. Luo, Evaluation of a seasonal storage system of solar energy for house heating using different absorption couples, Energy Convers. Manag. 52 (2011) 2427-2436. 
[3] K.A. Joudi, A.H. Lafta, Simulation of a simple absorption refrigeration system, Energy Convers. Manag. 42 (2001) 1575-1605.

[4] S. Jeong, B.H. Kang, S.W. Karng, Dynamic simulation of an absorption heat pump for recovering low grade waste heat, Appl. Therm. Eng. 18 (1998) 1-12.

[5] D.G. Fu, G. Poncia, Z. Lu, Implementation of an object-oriented dynamic modeling library for absorption refrigeration systems, Appl. Therm. Eng. 26 (2006) 217-225.

[6] P. Kohlenbach, F. Ziegler, A dynamic simulation model for transient absorption chiller performance. Part I: The model, Int. J. Refrigeration 31 (2008) 217-225.

[7] P. Kohlenbach, F. Ziegler, A dynamic simulation model for transient absorption chiller performance. Part II: Numerical results and experimental verification, Int. J. Refrigeration 31 (2008) 226-233.

[8] H. Matsushima, T. Fujii, T. Komatsu, A. Nishiguchi, Dynamic simulation program with object-oriented formulation for absorption chillers (modelling, verification, and application to triple-effect absorption chiller), Int. J. Refrigeration 33 (2010) 259-268.

[9] B. Bakhtiari, L. Fradette, R. Legros, J. Paris, A model for analysis and design of $\mathrm{H}_{2} \mathrm{O}-\mathrm{LiBr}$ absorption heat pumps, Energy Convers. Manag. 52 (2011) 1439-1448.

[10] H. Auracher, A. Wohlfeil, F. Ziegler, A simple model for steam absorption into a falling film of aqueous lithium bromide solution on a horizontal tube, Heat Mass Transfer 44 (2008) $1529-1536$.

[11] C. Flessner, S. Petersen, F. Ziegler, Simulation of an absorption chiller based on a physical model, Proceedings of the $7^{\text {th }}$ Modelica Conference, Como, Italy, 2009, pp. 312-317.

[12] J.D. Killion, S. Garimella, A critical review of models of coupled heat and mass transfer in falling-film absorption, Int. J. Refrigeration 24 (2001) 755-797.

[13] G. Grossman, Heat and mass transfer in film absorption, in: Cheremisinoff, N.P. (Ed.), Handbook of Heat and Mass Transfer, Vol. 2. Gulf Publishing Co., Houston, 1986, pp. 211257.

[14] S. Jeong, S. Garimella, Falling-film and droplet mode heat and mass transfer in a horizontal tube LiBr/water absorber, Int. J. Heat Mass Transfer 45 (2002) 1445-1458.

[15] E. Boudard, V. Bruzzo, Heat exchange and heat transfer device, in particular for a motor vehicle, European Patent 1751477B1 (2009).

[16] R.K. Shah, A.C. Mueller, Heat exchangers, in: Rohsenow, W.M., Hartnett, J.P., Ganic, E.N. (Eds.), Handbook of Heat Transfer Applications, $2^{\text {nd }}$ Edition. McGraw-Hill, New York, 1985, pp. 4.1-4.312.

[17] H. Kumar, The plate heat exchanger: construction and design, $1^{\text {st }}$ UK National Conference on Heat Transfer, University of Leeds, Inst. Chem. Symp, United Kingdom, 1984, Series 86, pp. 1275-1286. 
[18] C.C. Wang, C.J. Lee, C.T. Chang, S.P. Lin, Heat transfer and friction correlation for compact louvered fin-and-tube heat exchangers, Int. J. Heat Mass Transfer 42 (1999) 19451956.

[19] P. Griffith, Dropwise condensation, in: Schlunder, E.U., (Ed.), Heat Exchanger Design Handbook, Vol. 2, Hemisphere Publishing, New York, 1983.

[20] C.C. Wang, K.Y. Chi, C.J. Chang, Heat transfer and friction characteristics of plain finand-tube heat exchangers, part II : Correlation, Int. J. Heat Mass Transfer 43 (2000) 26932700 . 


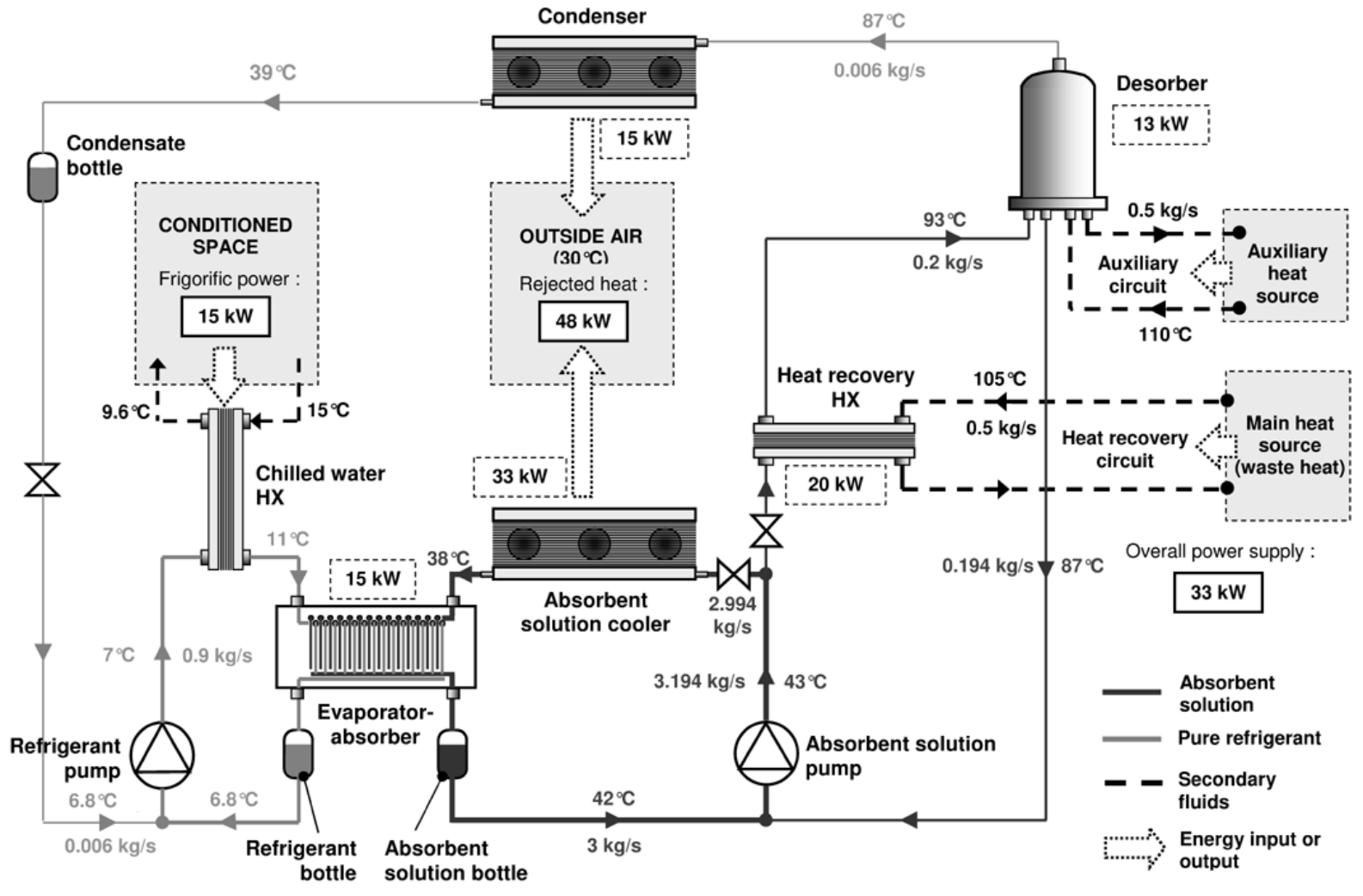

Figure 1 - Diagram of the complete chiller

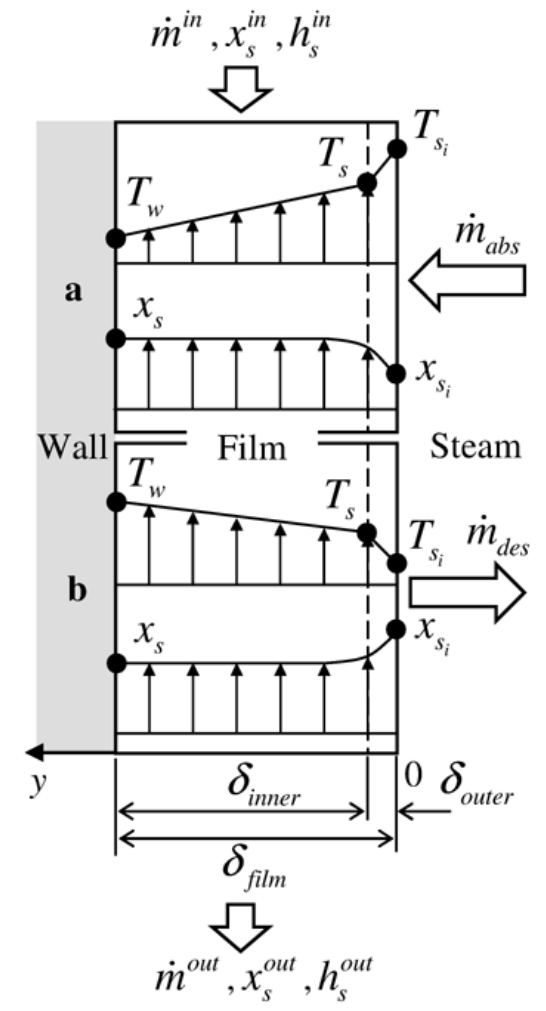

Figure 2 - Schematic of a modelled falling film, showing the temperature and $\mathrm{LiBr}$ concentration profiles. a) Absorption; b) Desorption 


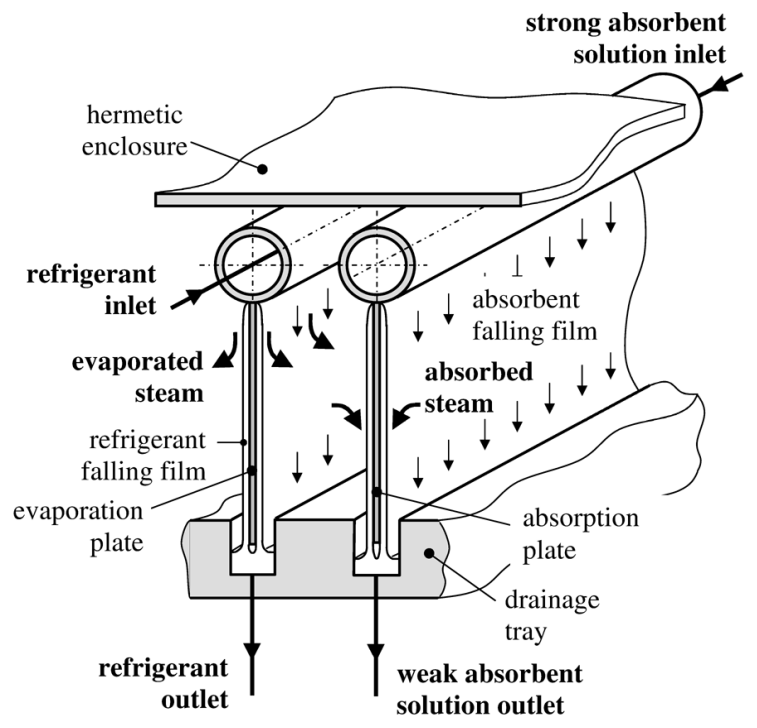

Figure 3 - Working principle of the evaporator-absorber

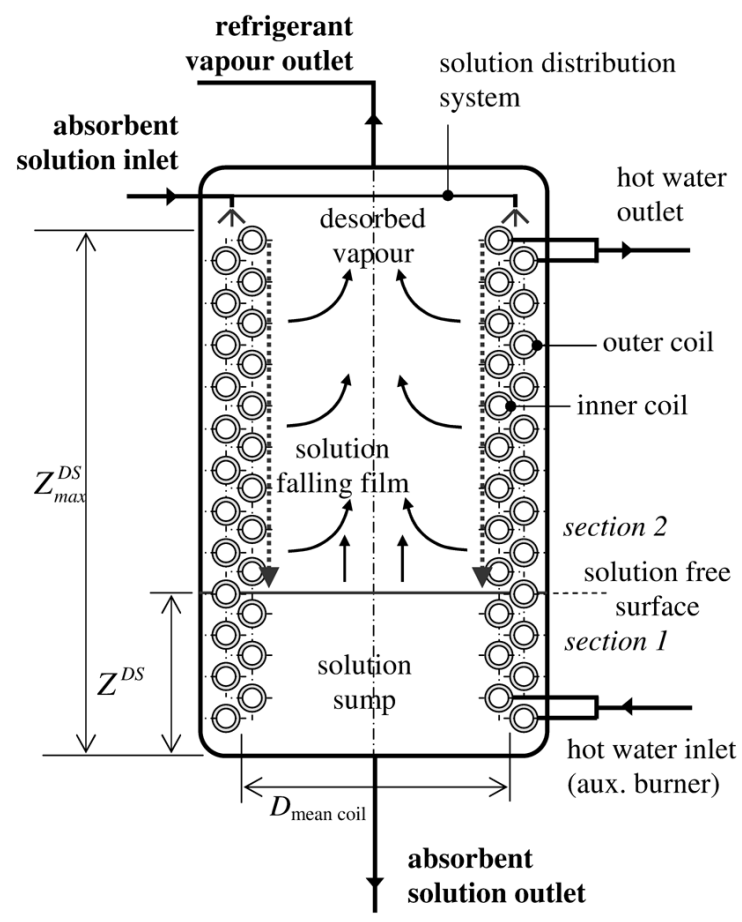

Figure 4 - Working principle of the desorber 


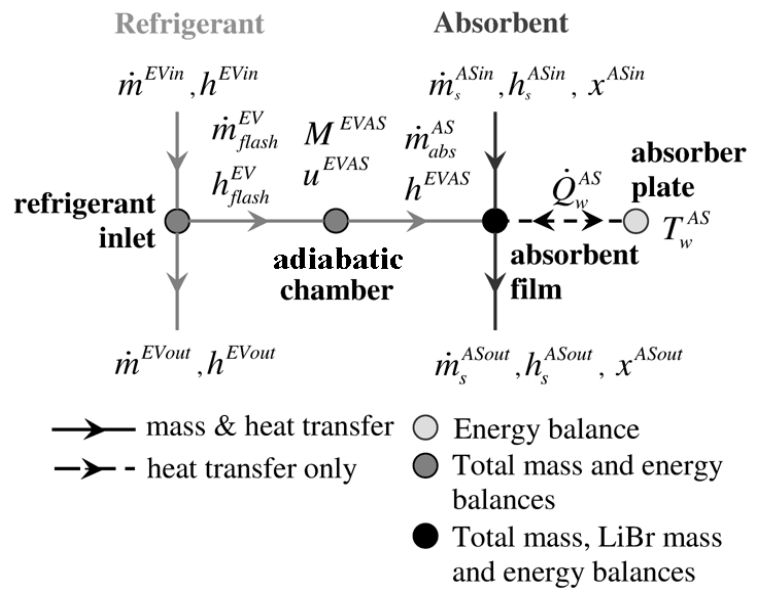

Figure 5 - Equivalent model diagram of the evaporator-absorber

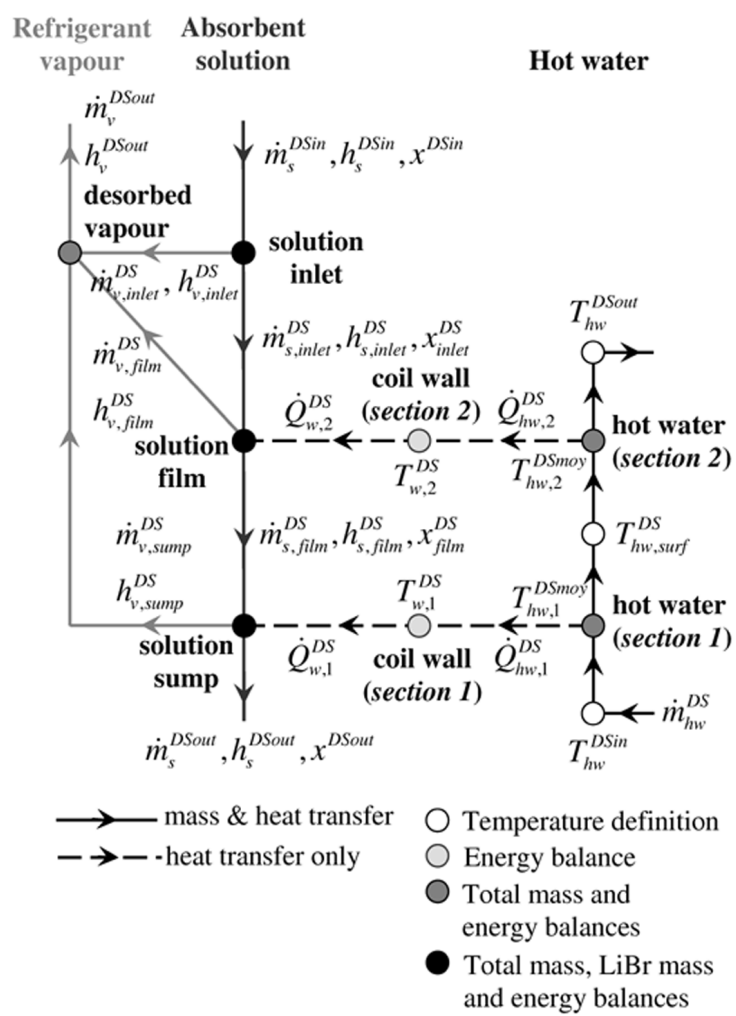

Figure 6 - Equivalent model diagram of the desorber 

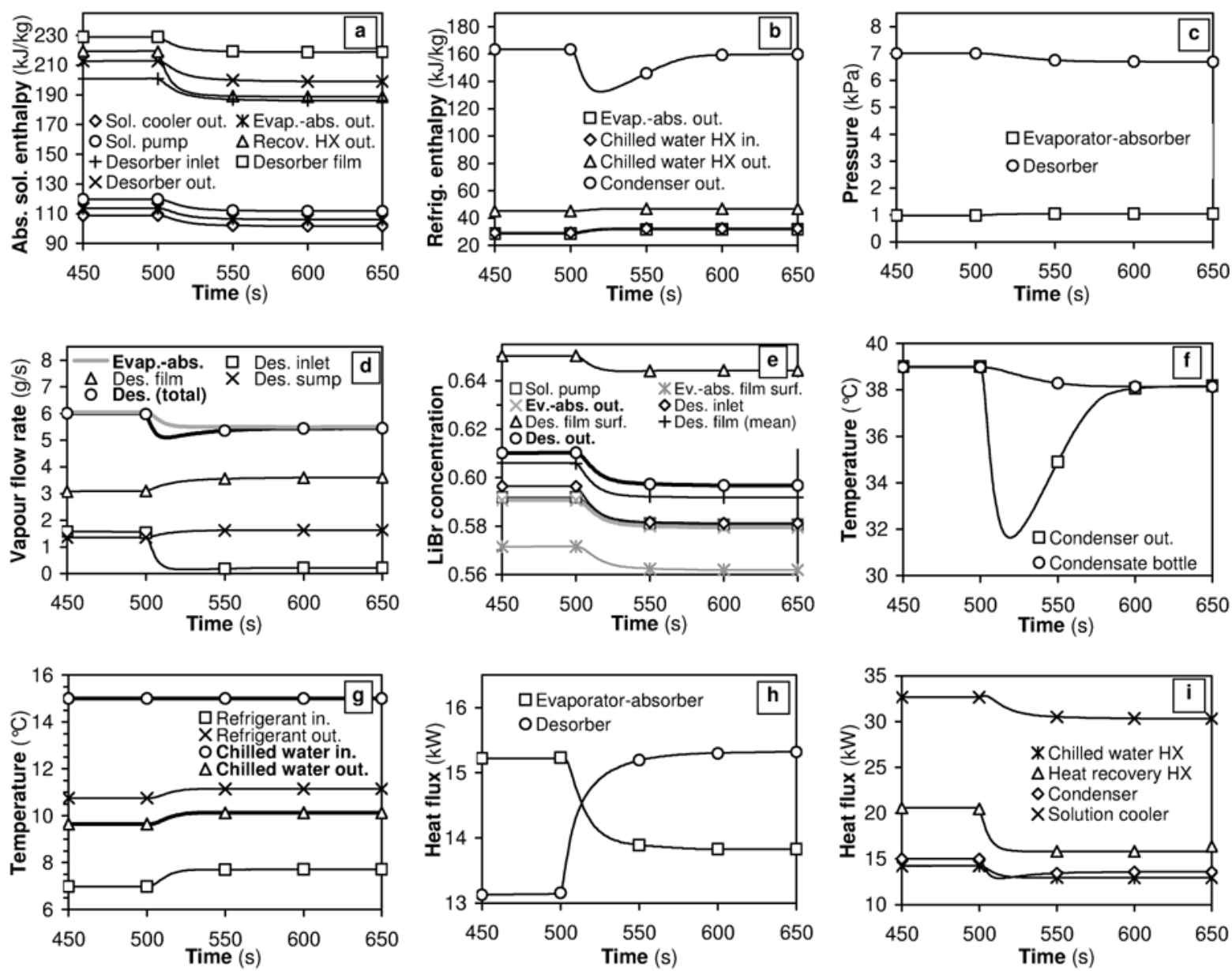

Figure 7 - Simulated chiller response on a heat recovery water flow rate reduction $(0.5 \mathrm{~kg} / \mathrm{s}$ to $0.17 \mathrm{~kg} / \mathrm{s}$ ), without regulation
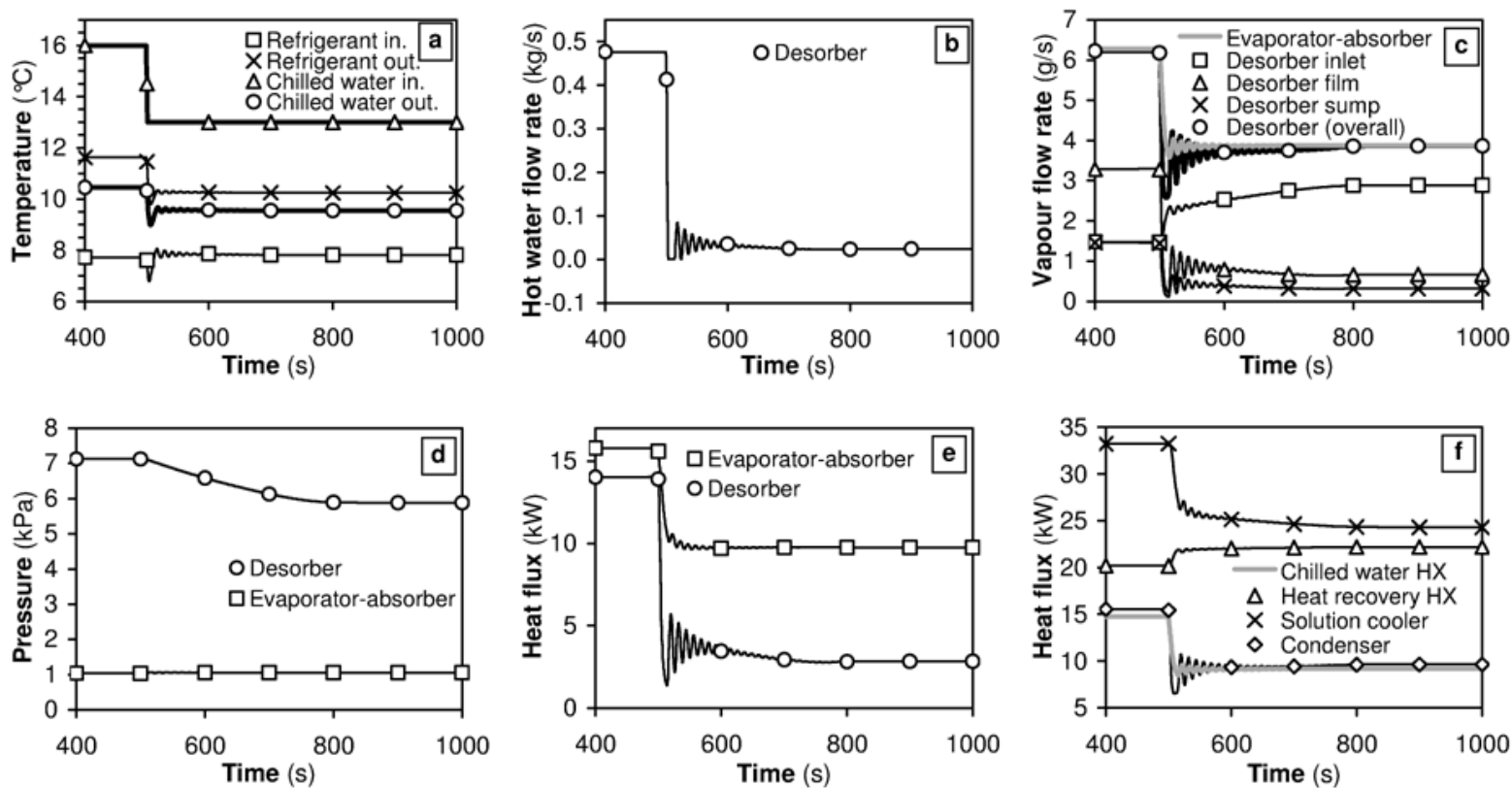

Figure 8 - Simulated chiller response on a chilled water inlet temperature change $\left(16^{\circ} \mathrm{C}\right.$ to $13^{\circ} \mathrm{C}$ ), with regulated chiller water outlet temperature $\left(\min : 9.5^{\circ} \mathrm{C}\right.$, max: $\left.10.5^{\circ} \mathrm{C}\right)$ 
TABLE 1 - Chilled water heat exchanger characteristics

\begin{tabular}{|c|c|c|c|}
\hline Feature & Unit & Hot Fluid Side & Cold fluid side \\
\hline Type & - & \multicolumn{2}{|c|}{ Welded plates } \\
\hline Configuration & - & \multicolumn{2}{|c|}{15 parallel plates } \\
\hline Fluid & - & Ethylene glycol & Water (refrigerant) \\
\hline Flow arrangement & - & 1 pass, counterflow & 1 pass, counterflow \\
\hline Mass flow rate & $\mathrm{kg} \cdot \mathrm{s}^{-1}$ & 0.72 & 0.90 \\
\hline Capacity rate & $\mathrm{kW} \cdot \mathrm{K}^{-1}$ & 2.7 & 3.8 \\
\hline H.T. surface & $\mathrm{m}^{2}$ & 1.5 & 1.5 \\
\hline H.T. coefficient & $\mathrm{kW} \cdot \mathrm{m}^{-2} \cdot \mathrm{K}^{-1}$ & 4.4 & 7.9 \\
\hline H.T. coeff. correlation ref. & - & Kumar [17] & Kumar [17] \\
\hline Overall H.T. coefficient & $\mathrm{kW} \cdot \mathrm{m}^{-2} \cdot \mathrm{K}^{-1}$ & \multicolumn{2}{|c|}{4.2} \\
\hline Number of transfer units & - & \multicolumn{2}{|c|}{1.6} \\
\hline Effectiveness & - & \multicolumn{2}{|c|}{0.67} \\
\hline Time constant & $\mathrm{s}$ & \multicolumn{2}{|c|}{1.75} \\
\hline
\end{tabular}


TABLE 2 - Absorbent solution cooler characteristics

\begin{tabular}{|c|c|c|c|}
\hline Feature & Unit & Hot Fluid Side & Cold fluid side \\
\hline Type & - & \multirow{2}{*}{\multicolumn{2}{|c|}{$\begin{array}{l}\text { Forced convection louvered fin-and-tube } \\
\qquad 66 \text { parallel coils }\end{array}$}} \\
\hline Configuration & - & & \\
\hline Fluid & - & LiBr solution & Air \\
\hline Flow arrangement & - & 6 passes, crossflow & 1 pass, crossflow \\
\hline Air velocity & $\mathrm{m} \cdot \mathrm{s}^{-1}$ & - & 2.5 \\
\hline Mass flow rate & $\mathrm{kg} \cdot \mathrm{s}^{-1}$ & 3.0 & - \\
\hline Capacity rate & $\mathrm{kW} \cdot \mathrm{K}^{-1}$ & 5.8 & 4.9 \\
\hline H.T. surface & $\mathrm{m}^{2}$ & 38 & 458 \\
\hline H.T. coefficient & $\mathrm{kW} \cdot \mathrm{m}^{-2} \cdot \mathrm{K}^{-1}$ & 1.7 & 0.099 \\
\hline H.T. coeff. correlation ref. & - & Dittus-Boelter & Wang et al. [18] \\
\hline Overall H.T. coefficient & $\mathrm{kW} \cdot \mathrm{m}^{-2} \cdot \mathrm{K}^{-1}$ & \multicolumn{2}{|c|}{26.6} \\
\hline Number of transfer units & - & \multicolumn{2}{|c|}{1.4} \\
\hline Effectiveness & - & \multicolumn{2}{|c|}{0.50} \\
\hline Time constant & s & \multicolumn{2}{|c|}{3.5} \\
\hline
\end{tabular}


TABLE 3 - Heat recovery heat exchanger characteristics

\begin{tabular}{lccc}
\hline \multicolumn{1}{c}{ Feature } & Unit & Hot Fluid Side & Cold fluid side \\
\hline Type & - & \multicolumn{2}{c}{ Welded plates } \\
Configuration & - & 33 parallel plates \\
Fluid & - & Ethylene glycol & LiBr solution \\
Flow arrangement & - & 1 pass & 16 passes \\
Mass flow rate & ${\mathrm{kg} . \mathrm{s}^{-1}}$ & 0.50 & 0.20 \\
Capacity rate & $\mathrm{kW} \cdot \mathrm{K}^{-1}$ & 1.9 & 0.40 \\
H.T. surface & $\mathrm{m}^{2}$ & 0.53 & 0.53 \\
H.T. coefficient & $\mathrm{kW} \cdot \mathrm{m}^{-2} \cdot \mathrm{K}^{-1}$ & 10.2 & 1.79 \\
H.T. coeff. correlation ref. & - & Kumar $[17]$ & Kumar [17] \\
Overall H.T. coefficient & $\mathrm{kW} \cdot \mathrm{m}^{-2} \cdot \mathrm{K}^{-1}$ & & 0.8 \\
Number of transfer units & - & & 2.0 \\
Effectiveness & - & & 0.79 \\
Time constant & $\mathrm{s}$ & 3 & \\
\hline
\end{tabular}


TABLE 4 - Condenser characteristics

\begin{tabular}{|c|c|c|c|}
\hline Feature & Unit & Hot Fluid Side & Cold fluid side \\
\hline Type & - & \multicolumn{2}{|c|}{ Forced convection plain fin-and-tube } \\
\hline Configuration & - & \multicolumn{2}{|c|}{2 rows of 60 parallel tubes } \\
\hline Fluid & - & Water (refrigerant) & Air \\
\hline Flow arrangement & - & 1 pass, crossflow & 1 pass, crossflow \\
\hline Air velocity & $\mathrm{m} \cdot \mathrm{s}^{-1}$ & - & 2.5 \\
\hline Mass flow rate & $\mathrm{kg} \cdot \mathrm{s}^{-1}$ & 0.005 & - \\
\hline Capacity rate & $\mathrm{kW} \cdot \mathrm{K}^{-1}$ & $\infty$ & 2.5 \\
\hline H.T. surface & $\mathrm{m}^{2}$ & 1.2 & 34 \\
\hline H.T. coefficient & $\mathrm{kW} \cdot \mathrm{m}^{-2} \cdot \mathrm{K}^{-1}$ & 131 & 0.078 \\
\hline H.T. coeff. correlation ref. & - & Griffith [19] & Wang et al. [20] \\
\hline Overall H.T. coefficient & $\mathrm{kW} \cdot \mathrm{m}^{-2} \cdot \mathrm{K}^{-1}$ & \multicolumn{2}{|c|}{2.6} \\
\hline Number of transfer units & - & \multicolumn{2}{|c|}{ de-superheating: 2.9 - 2-phase: 1.1 - subcooling: $\approx 0$} \\
\hline Effectiveness & - & \multicolumn{2}{|c|}{ de-superheating: 0.83 - 2-phase: 0.65 - subcooling: $\approx 0$} \\
\hline Time constant & $\mathrm{s}$ & \multicolumn{2}{|r|}{ 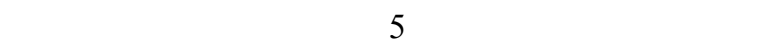 } \\
\hline
\end{tabular}


TABLE 5 - Initial steady-state input parameters

\begin{tabular}{|c|c|c|c|}
\hline Parameter & Symbol & Unit & Value \\
\hline Chilled water inlet temperature & $T_{c w}^{C W i n}$ & ${ }^{\circ} \mathrm{C}$ & 15 \\
\hline Chilled water mass flow rate & $\dot{m}_{c w}^{C W}$ & $\mathrm{~kg} \cdot \mathrm{s}^{-1}$ & 0.72 \\
\hline Outside air temperature & $T_{\text {air }}$ & ${ }^{\circ} \mathrm{C}$ & 30 \\
\hline Outside air velocity & $v_{\text {air }}$ & $\mathrm{m} \cdot \mathrm{s}^{-1}$ & 2.5 \\
\hline Heat recovery $\mathrm{HX}$ hot water inlet temperature & $T_{h w}^{H R i n}$ & ${ }^{\circ} \mathrm{C}$ & 105 \\
\hline Heat recovery $H X$ hot water mass flow rate & $\dot{m}_{h w}^{H R}$ & $\mathrm{~kg} \cdot \mathrm{s}^{-1}$ & 0.5 \\
\hline Desorber hot water inlet temperature & $T_{h w}^{D S i n}$ & ${ }^{\circ} \mathrm{C}$ & 110 \\
\hline Desorber hot water mass flow rate & $\dot{m}_{h w}^{D S}$ & $\mathrm{~kg} \cdot \mathrm{s}^{-1}$ & 0.4 \\
\hline Refrigerant pump mass flow rate (chilled water $\mathrm{HX}$ inlet) & $\dot{m}^{C W}$ & $\mathrm{~kg} \cdot \mathrm{s}^{-1}$ & 0.9 \\
\hline Regeneration loop mass flow rate (heat recovery $\mathrm{HX}$ inlet) & $\dot{m}^{H R}$ & $\mathrm{~kg} \cdot \mathrm{s}^{-1}$ & 0.2 \\
\hline Recirculation loop mass flow rate (solution cooler inlet) & $\dot{m}^{S C}$ & $\mathrm{~kg} \cdot \mathrm{s}^{-1}$ & 3.0 \\
\hline
\end{tabular}

